\title{
Investigation of recast and crack formation in laser trepanning drilling of CMSX-4 angled holes
}

\author{
Nicolau Iralal Morar ${ }^{1} \cdot$ Rajkumar Roy $^{1} \cdot$ Jörn Mehnen $^{2} \cdot$ Sundar Marithumu $^{3} \cdot$ Simon Gray ${ }^{1} \cdot$ Tracey Roberts $^{1}$. \\ John Nicholls ${ }^{1}$
}

Received: 22 May 2017 / Accepted: 13 December 2017 / Published online: 3 January 2018

(C) The Author(s) 2018. This article is an open access publication

\begin{abstract}
This paper presents an experimental investigation on the influences of laser trepanning drilling process parameters on the recast layer thickness and surface crack formation in CMSX-4 nickel-based superalloy angled holes. The effects of peak power, pulse frequency and the trepanning speed as input parameters were investigated in details by varying the laser drilling conditions using Taguchi orthogonal array-based design of experiment approach. Analysis of variance identifies the significant parameters affecting the output responses. It is found that the output responses are affected mainly by the peak power and trepanning speed. The experimental results reveal that the recast layer thickness increases with the increase of peak power and trepanning speed whereas the crack number density decreases with the increase of peak power only. Pulse frequency has no significant effect on both output responses within the range of values investigated. The knowledge gained in this parametric study could be used to improve the metallurgical characteristics of laser-drilled nickel-based acute angled holes.
\end{abstract}

Keywords Laser trepanning drilling $\cdot$ CMSX-4 $\cdot$ Recast layer $\cdot$ Surface cracks

\section{Introduction}

Pulsed Nd:YAG (neodymium-doped yttrium aluminium garnet) laser drilling is extensively used to produce holes of various sizes and shapes, in particular for the cooling film holes of hot section gas turbine components such as combustor liners, nozzle guide vanes and turbine blades. In comparison to electrical discharge machining (EDM), this process has a higher drilling rate [1], free of tool wear [2], capable of drilling ceramic coatings [3] and at a more acute angle than alternative processes [4]. As shown in Fig. 1, laser drilling in millisecond regime induces surface damage such as spatter [6], oxide and recast layer formation [7], heat-affected zone

Nicolau Iralal Morar

n.i.morar@cranfield.ac.uk

1 Department of Manufacturing and Materials, Cranfield University, Cranfield MK43 0AL, UK

2 Department of Design, Manufacture and Engineering Management, University of Strathclyde, Glasgow G1 1XQ, UK

3 Manufacturing Technology Centre (MTC), Ansty Business Park, Warwickshire, UK
(HAZ) [8] and burrs [9]. Among these, the recast layer is the most significant since it may contain oxide inclusions and microcracks [8]. This is highly undesirable particularly the presence of microcracks in the recast structure since the propagation of the cracks from the recast layer into the parent material could occur in service, leading to failure and thus compromising the integrity and lifetime of the drilled component.

Pulsed Nd:YAG laser drilling is a non-contact and thermalbased process, in which a high-power, pulsed focused laser beam is irradiated onto the workpiece surface to melt and vaporise the material to form a hole [2]. Elsewhere [10], it has been established that in a laser drilling process, four stages occur, viz. heating, melting, vaporisation and melt ejection. Further, in an attempt to understand the process better, some researchers have used observation techniques such as streak photography [11], field emission scanning electron microscope $[12,13]$ and high-speed cameras [14] to describe the material removal mechanism and surface characteristics during the laser drilling.

Various authors including $[1,4,15]$ discussed two laser drilling methods currently used for the manufacture of cooling holes for gas turbine hot section components, viz. percussion and trepanning. Percussion drilling method involves a fixed 
Fig. 1 Schematic of the physical damages taking place during the nanosecond/millisecond laser drilling process, adopted from Dimov et al. [5]

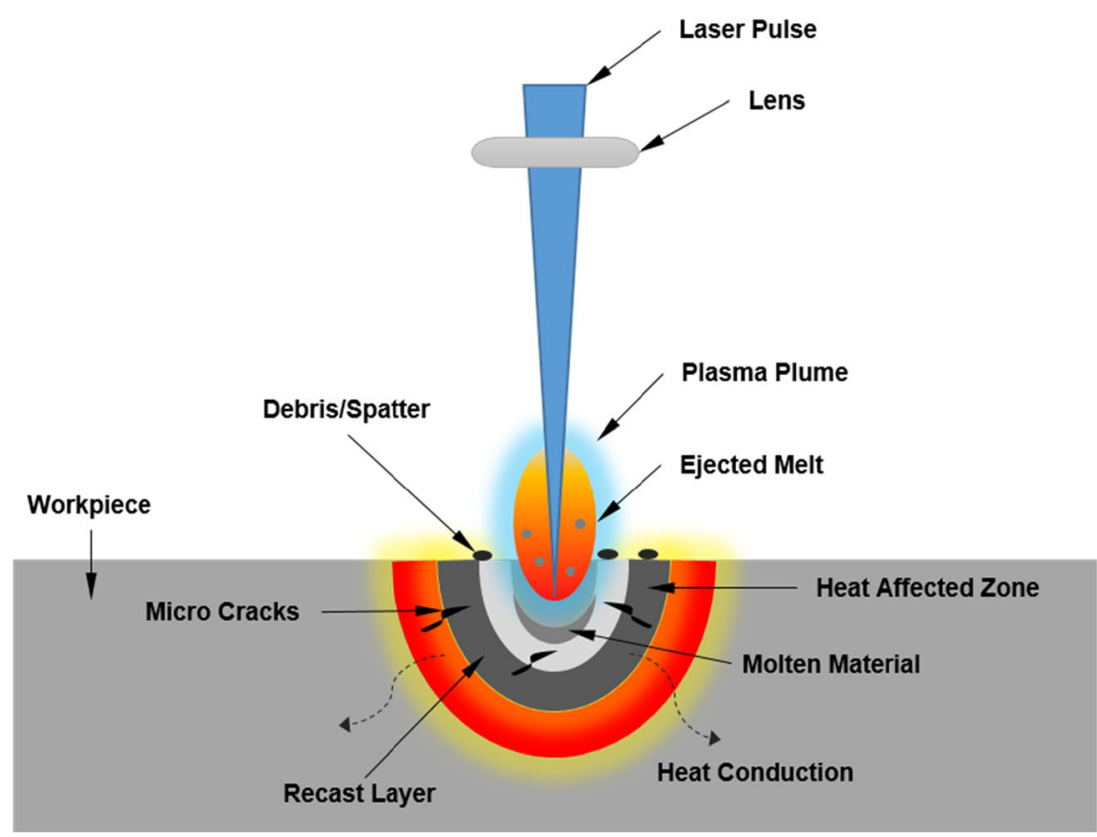

laser beam, firing one or more pulses into the workpiece until the hole is produced. This method provides a reduction in drilling time compared to the trepanning method by a factor of 4 [8]. However, this increase in speed is normally at the expense of quality of the hole.

In the present study, the trepanning method was used, since it is a preferred and established method for the drilling of high-quality holes ranging from 0.5 to $1.0 \mathrm{~mm}$ in diameter [16]. This method provides a better geometrical and metallurgical quality than the current percussion methods [17]. A schematic layout of the laser trepanning drilling process is depicted in Fig. $2 \mathrm{a}-\mathrm{d}$. The process starts with a focused laser beam initially piercing a pilot hole at the centre by percussion drilling (see Fig. 2b) and then sweeps out to the circumference moving in a circular path to cut the edge of a hole to the size; see Fig. 2c, d.

The literature survey on the pulsed Nd:YAG laser drilling of nickel-based superalloys shows a considerable number of studies conducted on the percussion method compared to the trepanning method. The effect of pulsed Nd:YAG laser percussion drilling process parameters on the geometrical [18-20] and metallurgical [21-23] quality characteristics has been established in previous studies.

Conversely, there are a very limited number of research studies relative to pulsed $\mathrm{Nd}$ :YAG laser trepanning drilling of nickel-based super alloys. Horn et al. [24] examined the effects of three assist gases nitrogen, argon and oxygen on the recast layer thickness (RLT) and cracking in coated CMSX-4 laser trepanned drill holes at an acute angle up to $60^{\circ}$ to the surface. The results showed that the RLT was at least two to three times less when using argon assist gas in comparison to oxygen and nitrogen during trepanning laser drilling. The presence of cracks and bubbles in the recast layer was observed when using oxygen, and argon found to be the most effective process gas when it comes to reducing the thickness of the recast layer. However, argon gas forms burrs that are difficult to remove. In current manufacturing, oxygen and air are the two main gases used as this gives an acceptable balance of process speed and metallurgical result [25].

Willach et al. [26] examined the effects of assist gas pressure, nozzle diameters and nozzle distance on trepanning kerf and the recast layer thickness during laser trepanning drilling of CMSX-4. The results revealed that the high assist gas pressure and larger nozzle diameter improve the melt expulsion and reduces the RLT. Further, an increase of nozzle distance to the workpiece surface leads to a thicker recast layer. Lugscheider et al. [27] applied finite volume method to investigate the gas jet of the conical nozzle positioned above the workpiece surface and found that lateral offset of the nozzle yields a smaller recast layer at the trepan kerf surface during angle drilling. Kreutz et al. [28] presented a five-axis trepanning drilling process for low-angled and fan-shaped holes with minimum damage to the coated CMSX-4 substrate. They found that five-axis trepanning of shaped holes yields high reproducibility and thin recast layer thickness. They also suggested that the use of oxygen assist gas prevents closures, melt droplets and formation of burrs compared to process argon. However, the choice of gas does not reflect the current industrial practice across the number of applications.

Chien and Hou [29] applied Taguchi method to investigate the parameters that exert more influence on the recast layer formation during laser trepanning drilling of Inconel 718. The experimental results showed that gas pressure, peak power and focal length are significant factors affecting the RLT. 
Fig. 2 Schematic representation of a laser trepanning drilling process

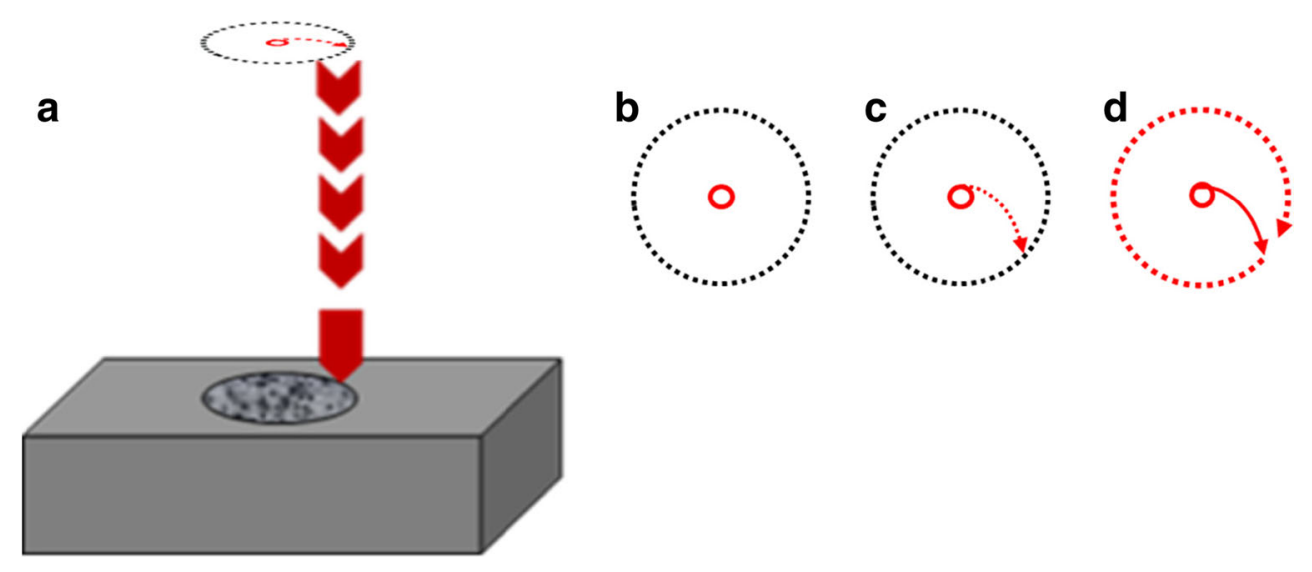

Further experiments and analysis concluded that the minimum recast layer thickness can be obtained by adjusting the values of the assist gas pressure and the trepanning speed. Wang et al. [30] also used the Taguchi method to examine the influence of laser trepanning drilling parameters (peak power, pulse width and pulse frequency) on a Ni-based superalloy. They found that the pulse width (duration) had a significant effect on the RLT. In addition, laser post-processing by chemical etching can remove the residual recast layer completely.

More recently, Kumar et al. [31] developed a computeraided hybrid methodology of multi-variable regression and genetic algorithm for multi-objective optimisation (CGAMO) to predict the recast layer at the entrance and exit of Inconel 718 laser trepanned drill holes. They used the published experimental data [29] for training, for testing and for validating the software toolset. The CGAMO toolset suggested that based on the range of values used, the low RLT at entrance hole could be achieved at lower values of peak power and higher values of assisting gas pressure, and low recast layer at the exit hole could be obtained at lower values of nozzle diameter as well as low values of peak power. Goyal and Dubey [17] adopted artificial neural network and genetic algorithm to obtain optimal laser drilling parameters for better hole circularity and reduced taper on the Inconel 718 alloy. They found that the higher values of pulse frequency and trepanning speed resulted in better geometrical characteristics (hole taper and circularity). Also, previous studies [32, 33] found that the pulse shaping improves the taper ratio and improves the metallurgical quality of the holes.

Despite a limited number of publications on this laser drilling method, no studies have reported in detail the relationship between the $\mathrm{Nd}$ :YAG laser trepanning drilling process parameters, recast layer thickness and surface crack formation in CMSX-4 nickel-based superalloy acute angled holes. In view of that, this experimental study is an attempt in this direction. Statistical techniques were used for the design of experiments and post-experiment analysis. The effects of peak power, pulse frequency and trepanning speed were investigated in detail.
Fig. 3 Laser machine and experimental set-up used for the drilling of the samples (Courtesy of MTC, Ansty)

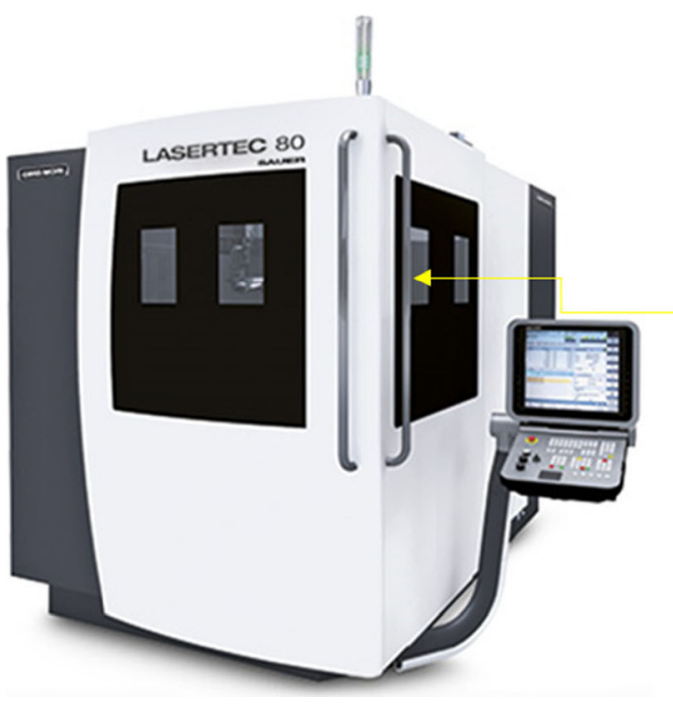

Laser Beam Head

Beam Nozzle

Workpiece

5-axis Working Table 
Table 1 Control factors and their levels

\begin{tabular}{llccc}
\hline Symbol & Control parameters & Level 1 & Level 2 & Level 3 \\
\hline A & Peak power $(\mathrm{kW})$ & 8.3 & 10.0 & 12.5 \\
B & Pulse frequency (Hz) & 20 & 22.5 & 25 \\
C & Trepanning speed (mm/min) & 75 & 100 & 125 \\
\hline
\end{tabular}

\section{Experimental}

\subsection{Material}

CMSX-4® ${ }^{1}$ nickel-based superalloy is used as workpiece material in the experiments. The samples were in the form machined rectangular plates of $65 \mathrm{~mm} \times 8 \mathrm{~mm} \times 2 \mathrm{~mm}$ dimensions. The chemical composition in wt\% of CMSX-4 is as follows: Al 5.6; Cr 6.5; Co 9.6; W 6.4; Re 3.0; Mo 0.6; Ti 1.0; Ta 6.5; Hf 0.1; Ni balance [34]. Before the laser drilling, the samples were cleaned with acetone and coated with antispatter silicon-base paste as to minimise the substrate surface damage from spatter and debris.

\subsection{Laser drilling}

A five-axis LASERTEC 80 PowerDrill machine, fitted with a $300 \mathrm{~W}$ millisecond pulsed Nd:YAG laser source at a wavelength of $1.064 \mu \mathrm{m}$, was used for the experiments. All experiments were performed at a laser beam inclination angle of $30^{\circ}$ to the workpiece surface and hole diameter approximately of $0.75 \mathrm{~mm}$. A nozzle assembly with a focusing lens of $170 \mathrm{~mm}$ length, nozzle stand-off distance of $10 \mathrm{~mm}$ and nozzle exit diameter of $2.0 \mathrm{~mm}$ was used in the experiment. The laser focal position was always on the workpiece surface $(0 \mathrm{~mm})$, and two trepanning orbits were used for the entire experiment. An oxygen assist gas at a pressure of 100 psi was used throughout the study (Fig. 3).

\subsection{Design of experiments}

Taguchi method L9 orthogonal array (OA) based design of experiments was employed and found to be suitable for the selected three main control factors and their ranges based on the available literature [35]. This method allowed the number of trials required to be minimised compared to the classical combination method with the full factorial experiment, which would have required 36 experimental runs to capture the influencing parameters. Moreover, the L9 OA had three columns and nine rows providing eight degrees of freedom to manipulate three control parameters with three levels. The control factors and their levels are presented in Table 1.

\footnotetext{
${ }^{1}$ CMSX-4 is a registered trademark of Cannon-Muskegon Corporation.
}

The quality characteristics of control parameters are evaluated using a signal to noise $(\mathrm{S} / \mathrm{N})$ ratio. In this work, the 'smaller is better' (SB) quality characteristic was chosen for the analysis of the maximum of recast layer thickness $\left(\mathrm{RLT}_{\max }\right)$ and transverse microcrack number density $\left(\mathrm{TCND}_{\max }\right)$ observed. Based on the Taguchi method, the $\mathrm{S} / \mathrm{N}$ ratio equation and analysis of variance (ANOVA) related equations can be found in the literature [35]. Moreover, the software MINITAB v17 was used to compute the $\mathrm{S} / \mathrm{N}$ ratios and ANOVA to explore the effects of each laser trepanning drilling parameter on the observed values and reveal which laser drilling parameters significantly influenced the observed values. Moreover, four-hole replication at each trial was performed in order to minimise the error effects during the experiments and measurements.

\subsection{Microstructural analysis}

After laser drilling, the specimens were cleaned and vapour blasted to remove the anti-spatter coating and excess of debris (see Fig. 4). Then, the laser-drilled plates each containing nine trials with four-hole replication were longitudinal and transverse cross-sectioned to a single trial sample. These section samples were then mounted in a conductive black phenolic resin, followed by grinding (to the middle of the laser-drilled hole) with silicon carbide papers (240, 1200 and 2500 grade) and fine polishing with a microcloth disc embedded with colloidal silica $(0.05 \mu \mathrm{m})$ solution. The mounted samples were then etched using standard electrolytic etching technique procedure in order to reveal the recast structure, as described by Sezer et al. [8].

The recast structure was first analysed using a Nikon (Eclipse ME600) optical microscope. The RLT measurements were recorded under $\times 5$ and $\times 10$ magnification in 16 different locations equally spaced along the leading edge and trailing edge of each hole cross section, as shown in Fig. 5. An average of maximum values at each four holes was used for the analysis to minimise the measurement errors at each trial.

Further, the recast structure examination was performed using scanning electron microscopy (SEM; Oxford FG-16) with backscattered electron (BSE) signals to fully inspect the microcracks in the recast layer. The number of cracks and their length found in each trial sample were recorded. The calculation of the surface crack number density (CND) is done by taking number of maximum microcrack in the recast layer out of the four holes at each trial and dividing by the depth of the hole times the long axis of the hole (see Fig. 6). The HAZ observed below the recast structure was negligible $(\approx 5 \mu \mathrm{m})$. The oxide layer observed above the recast layer was not considered in the present study. These were being poorly adhered to the recast, and it is, in general, removed during the post-laser drilling. Moreover, HAZ, the oxide layer and burr formation were out of the scope of this study. 
Fig. 4 Example of a section of CMSX-4 sample a before laser drilling, $\mathbf{b}$ after laser drilling with anti-spatter coating and $\mathbf{c}$ with anti-spatter coating removed
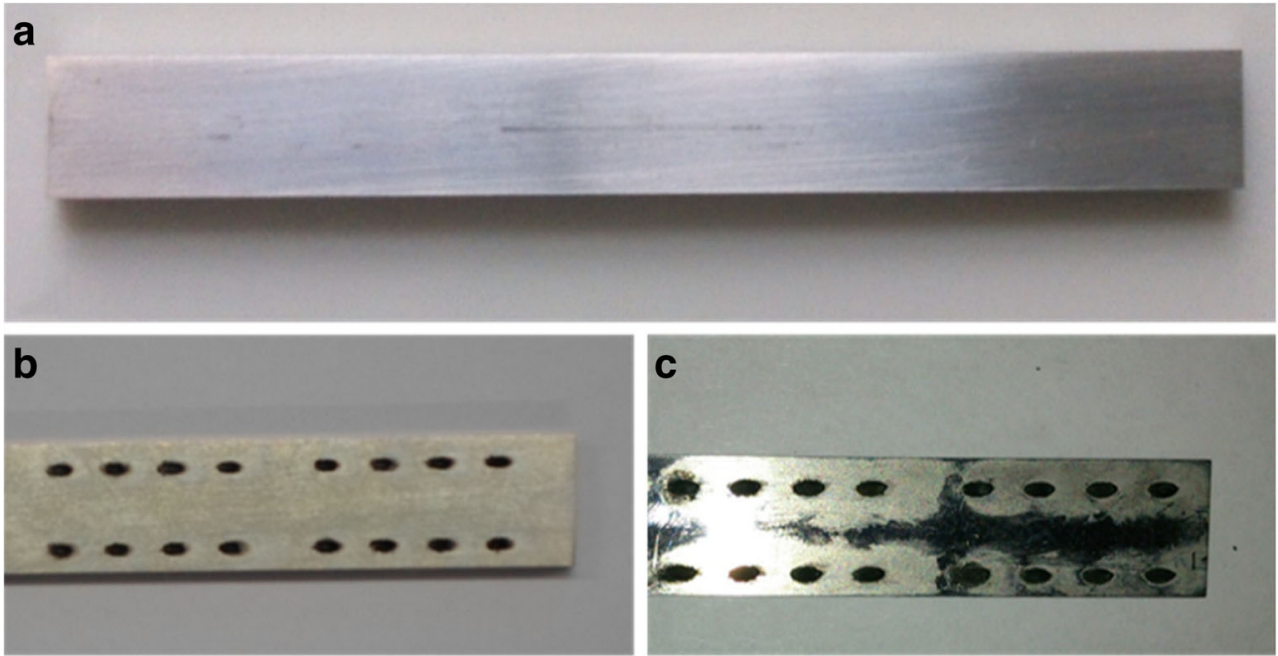

\section{Results and discussion}

\subsection{Surface characteristics}

Figure 7 shows an example of surface alterations after laser trepan drilling process. In the laser trepanning drilling process, the molten material formed due to intense laser beam energy is ejected towards the exit hole by assist process gas. However, a fraction of this molten material is also quickly re-solidified and adheres to the sidewalls of the hole surface due to the rapid cooling effect of the assist process gas, leaving a hard and brittle layer called the recast layer. The recast layer may contain oxide inclusions, globules and microcracks, as depicted in Fig. 7. The recast layer in laser-drilled holes becomes more detrimental if the microcracks are present. These cracks are susceptible to propagate under service conditions, from the recast layer into the parent material, hence may limit the in-service life of a laser-drilled component.

The microcracks in the laser-drilled holes are formed due to the thermal mismatch between the laser beam energy and the cold workpiece, and subsequent cooling effect induced by assist process gas during the laser processing. This causes large temperature gradients near the hole surface. The microcracks observed in the recast layer are predominantly longitudinal and transverse; see Fig. 7. The longitudinal microcracks are along the length of the hole and can flake off in layers. The transverse microcracks are perpendicular to the recast layer starting at the oxide layer and may penetrate the entire recast layer thickness, and in some cases extending into the base material. Therefore, only transverse crack number density $\left(\mathrm{TCND}_{\max }\right)$ was used and considered for the analysis of this work. The severity of the RLT and
Fig. 5 Optical micrograph showing the recast layer thickness measurement at different points on the cross section of a laserdrilled hole

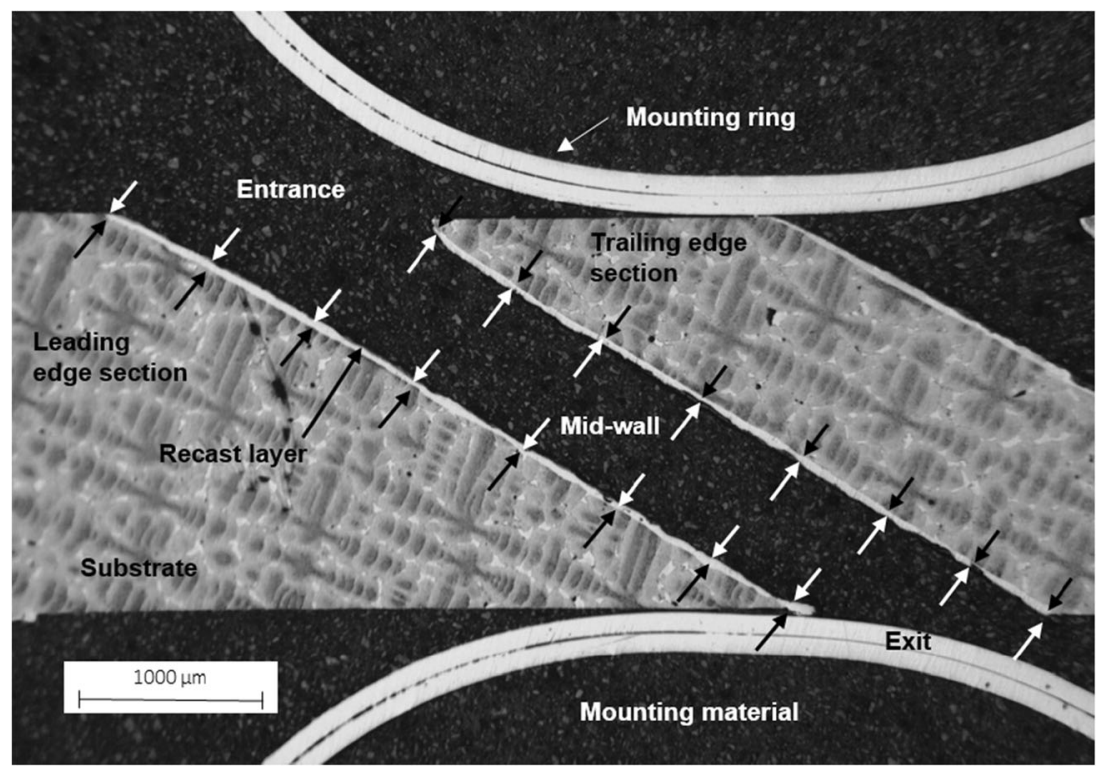




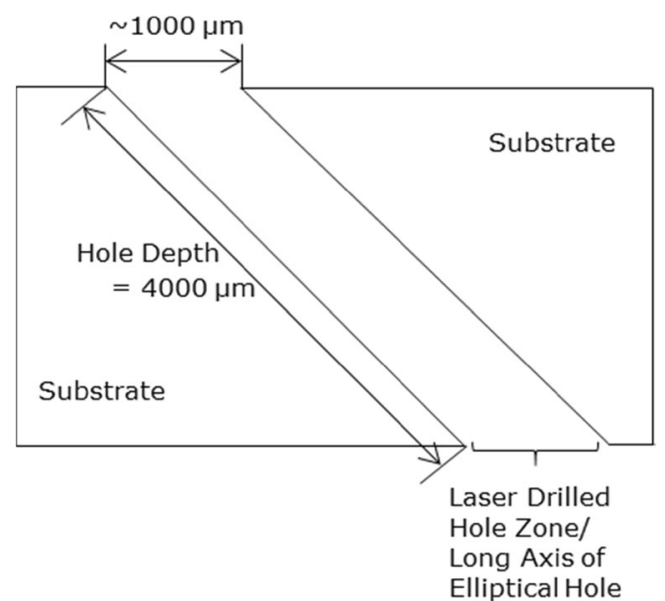

Fig. 6 Schematic of cross-sectioned profile showing the examined area of unit for crack number of density

TCND is depending on the laser drilling parameters used, as it is shown in Fig. 8 .

Figure 8a shows the laser trepanned drill hole surface at trial 3 of the L9 OA parameter setting. The surface morphology shows that the recast layer is spread unevenly on the drilled surface so as the above oxide layer. The presence of microcracks is predominately in the oxide layer due to the thermal stresses and rapid cooling effect during the processing. The oxide layer observed is caused by the intense laser beam energy and exothermic reaction by the oxygen assist process gas. This oxidises the top layer of the recast surface, and in some cases, the oxides diffuse into the recast forming oxide inclusions, as shown in Fig. 7. The average RLT $_{\max }$ value measured at this parameter setting was greater than $75 \mu \mathrm{m}$, and the
$\mathrm{TCND}_{\max }$ on the recast layers was less than 2.0 no./ $\mathrm{mm}^{2}$. One reason is that high trepanning speed employed in this parameter setting (trial 3) reduces the laser beam and workpiece surface interaction time. The trepanning speed is very important in pulsed mode since it controls the extent of beam spot overlap at the surface of the workpiece, which is directly responsible for the RLT formation.

Figure $8 \mathrm{~b}$ shows the laser trepanned drill hole at trial 8 of the L9 OA parameter setting. The SEM observations show discrete localised pools of the oxidising layer along with cracking and in some cases penetrating into the recast layer. The average $\mathrm{RLT}_{\max }$ value is higher having its value greater than $65 \mu \mathrm{m}$. This increase in the recast layer thickness could be because of the high peak power and high trepanning speed interaction at this setting. This is because as previously mentioned that at faster trepanning speed, the beam interaction time with workpiece surface is less and the heat generated at high peak power results in more melt at the cut front than vaporisation and melt ejection at end of each pulse, thus thicker RLT. Interestingly, the $\mathrm{TCND}_{\max }$ at this setting was at its lowest from the entire L9 experimental trials. This is due to short pulse duration at this setting induced less thermal stress. Moreover, this observation is also seen in the trials tested at the maximum peak power level, trials 7 and 9 .

Figure $8 \mathrm{c}$ shows the laser trepanned drill hole at trial 4 of the L9 OA parameter setting. The effect of increasing peak power from levels 1 to 2 shows less oxide layer hence a gradual decrease of the recast layer thickness. However, the degree of microcrack formation increased, extending more to the recast/substrate interface. This is because the combination of peak power level used and pulse time at this setting had a
Fig. 7 Example of a scanning electron microscopy image showing typical metallurgical anomalies after laser drilling (trial 2, A1B2C2)

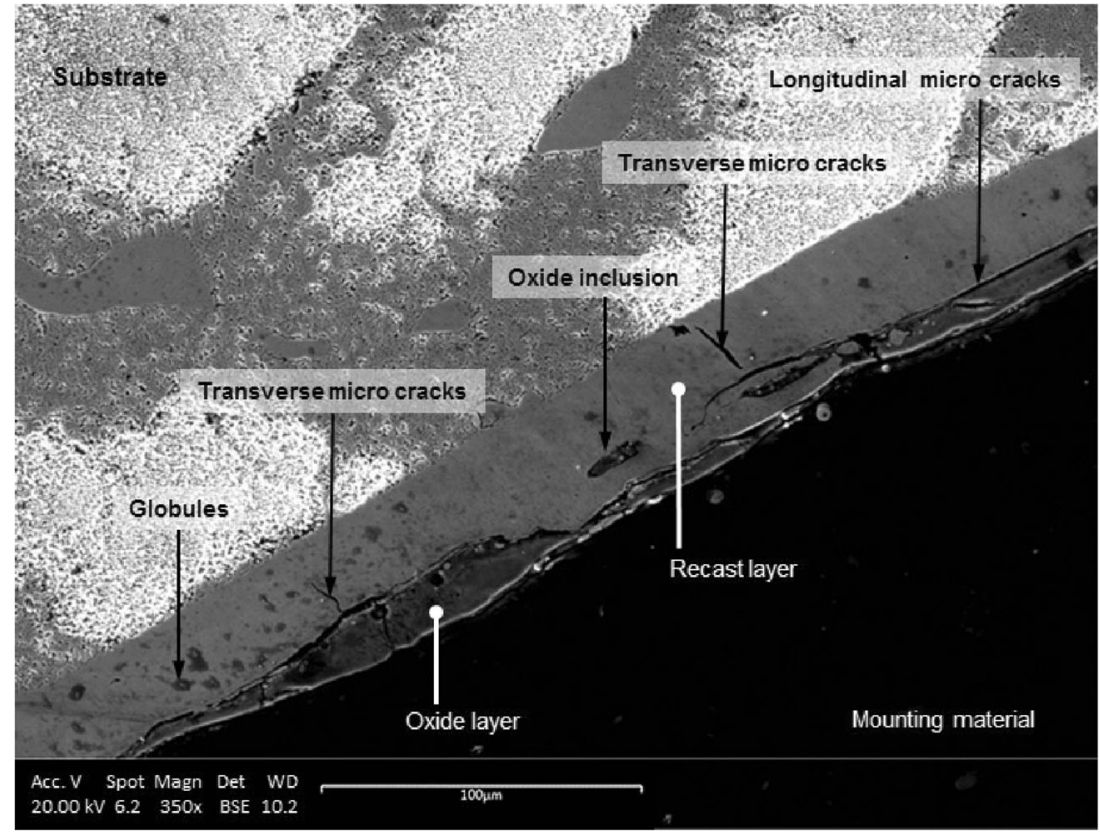



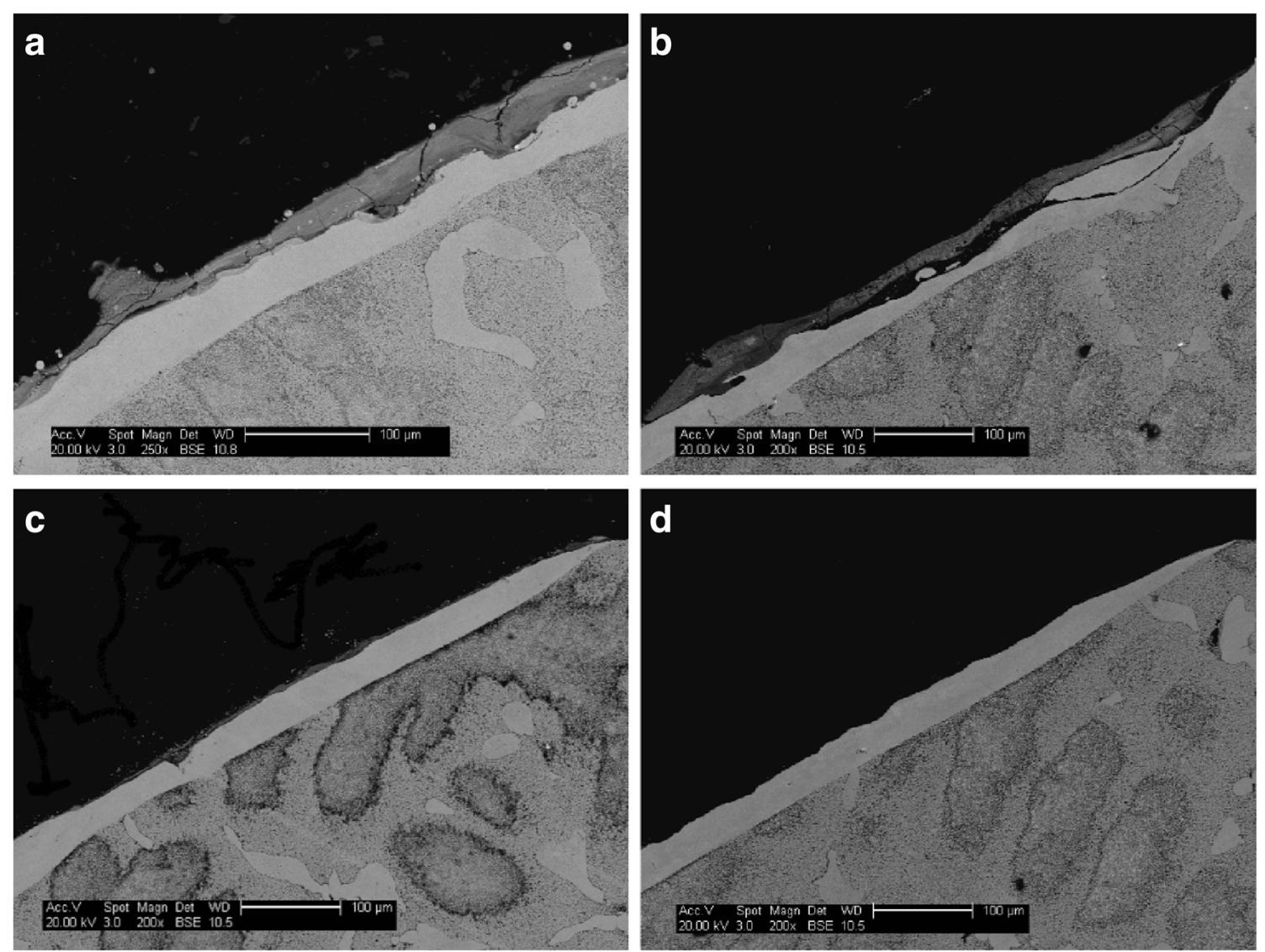

Fig. 8 SEM micrographs of nickel-based CMSX-4 laser trepanned acute angle drill hole surfaces at different parameter settings. a Trial 3, A1B3C3. b Trial 8, A3B2C1. c Trial 4, A2B1C2. d Trial 6, A2B3C1

greater tendency to induce thermal stress, and hence, cracks are readily formed within the recast layer. No microcracks were observed in the substrate in this parameter setting.

Figure $8 \mathrm{~d}$ shows the laser trepanned drill hole at trial 1 of the L9 OA parameter setting indicating a low value of average $\mathrm{RLT}_{\text {max }}$ as well as a decrease on the number microcracks. This response could be due to the effect of low peak power and low trepanning speed interaction resulted in a robust laser beam and workpiece surface interaction which led to an effective melting, higher vaporisation rate and efficient melt ejection, as well as less thermal damage to the hole surface.

\subsection{Taguchi analysis}

Table 2 shows the maximum recast layer thickness $\left(\mathrm{RLT}_{\max }\right)$ and the transverse crack number density $\left(\mathrm{TCND}_{\max }\right)$ and their respective $\mathrm{S} / \mathrm{N}$ ratios obtained from the $\mathrm{L}$ 9 OA-based experimental trials. The analysis of variance (ANOVA) was used in order to test the statistical significance of the main factors for the $\mathrm{RLT}_{\max }$ and the $\mathrm{TCND}_{\max }$. The preferable combination levels of the laser trepanning drilling to minimise the $\mathrm{RLT}_{\text {max }}$ and $\mathrm{TCND}_{\max }$ were also determined under the mean $\mathrm{S} / \mathrm{N}$ ratio response table (see Table 3 ). The interpretation of the results is discussed in Sects. 3.2.1 and 3.2.2.
The lowest values of recast layer thickness and number density of cracks are very crucial for surface integrity enhancement and to reduce the detrimental effect on the fatigue life of laser-drilled components. Therefore, the 'smaller is better' (SB) quality objective characteristic was employed for the present analysis, as mentioned in Sect. 2.3. The smaller is better characteristic is calculated using Eq. 1, where $\eta$ : signal to noise ratio ( $\mathrm{S} / \mathrm{N}$ ratio), $y_{i}$ : the $i$ th response of the experiment and $n$ : the repeated number of the $i$ th experimental trial [35].

$\eta=-10 \log \left[\frac{1}{n} \sum_{i=1}^{n} y_{i}^{2}\right]$

$\mathrm{S} / \mathrm{N}$ ratio for smaller is better $(\mathrm{SB})$.

\subsubsection{Recast layer}

In pulsed Nd:YAG laser drilling process, the intensity of the laser energy causes the irradiated area to melt and vaporise in a fraction of milliseconds per pulse. With each pulse, the molten material is removed and a hole is formed in the drilled surface. The presence of the recast layer thickness is caused by the physics of the removal of the molten material that is generated during the laser drilling process. The molten material removal 
Table 2 L9 OA experimental results of $\mathrm{RLT}_{\max }$, number of $\mathrm{TCND}_{\max }$ and their $\mathrm{S} / \mathrm{N}$ ratios

\begin{tabular}{|c|c|c|c|c|c|c|c|}
\hline \multirow[t]{2}{*}{ Trial } & \multicolumn{3}{|c|}{$\begin{array}{l}\text { Level of control } \\
\text { parameters }\end{array}$} & \multicolumn{2}{|l|}{ Response } & \multicolumn{2}{|l|}{$\mathrm{S} / \mathrm{N}$ ratios } \\
\hline & A & $\mathrm{B}$ & $\mathrm{C}$ & Average, $\mathrm{RLT}_{\max }(\mu \mathrm{m})$ & $\mathrm{TCND}_{\max }\left(\mathrm{no} . / \mathrm{mm}^{2}\right)$ & $\mathrm{RLT}_{\text {max }}(\mathrm{dB})$ & $\mathrm{TCND}_{\max }(\mathrm{dB})$ \\
\hline 1 & 1 & 1 & 1 & 48.3 & 1 & -33.67 & 0.000 \\
\hline 2 & 1 & 2 & 2 & 55.3 & 2 & -34.85 & -6.020 \\
\hline 3 & 1 & 3 & 3 & 77.1 & 1.25 & -37.74 & -1.938 \\
\hline 4 & 2 & 1 & 2 & 53.0 & 1.5 & -34.48 & -3.521 \\
\hline 5 & 2 & 2 & 3 & 64.5 & 2.75 & -36.19 & -8.786 \\
\hline 6 & 2 & 3 & 1 & 50.0 & 2.5 & -33.97 & -7.958 \\
\hline 7 & 3 & 1 & 3 & 68.7 & 1.25 & -36.73 & -1.938 \\
\hline 8 & 3 & 2 & 1 & 61.8 & 0.25 & -35.81 & 12.041 \\
\hline 9 & 3 & 3 & 2 & 63.4 & 0.5 & -36.04 & 6.020 \\
\hline
\end{tabular}

occurs through the vaporisation and ejection, as previously mentioned. The proportion of melt, molten vaporisation and ejection depends on the parameters used and the optical set-up; hence, the recast layer thickness solely depends on the efficiency of removal. Figure 9 shows the effects of the input control parameters on the average RLT $\mathrm{T}_{\max }$.

It can be seen from the main effect plot Fig. 7 that average $\mathrm{RLT}_{\text {max }}$ increases with the peak power and trepanning speed. The trend in the response plot 9(A) can be explained as follows. The pulse energy and pulse duration combination sets laser peak power. The laser peak power is the amount of energy delivered onto a target surface to melt and vaporise during a single pulse. Short pulse duration with constant high pulse energy will give a high laser peak power. This highintensity power causes more molten material than vaporisation and thus leaving a significant amount of resolidified material around the walls of the laser-drilled holes. As the peak power decreases, a lower laser intensity irradiates the target surface causing less molten material and high evaporation rate, and as a result, in a reduction of the recast layer. However, as the laser peak power gets too low due to the longer pulse duration, the vaporisation rate decreases causing more molten material around the wall of the drilled surface, resulting in an increase of the recast layer thickness.

Table 3 Mean response table for signal to noise $(\mathrm{S} / \mathrm{N})$ ratios

\begin{tabular}{|c|c|c|c|c|c|c|}
\hline \multirow[t]{2}{*}{ Levels } & \multicolumn{3}{|c|}{ Average, $\mathrm{RLT}_{\max }(\mathrm{dB})$} & \multicolumn{3}{|c|}{$\mathrm{TCND}_{\max }(\mathrm{dB})$} \\
\hline & A & $\mathrm{B}$ & $\mathrm{C}$ & A & $\mathrm{B}$ & $\mathrm{C}$ \\
\hline 1 & -35.42 & -34.97 & -34.49 & -2.65 & -1.29 & 1.36 \\
\hline 2 & -34.89 & -35.62 & -35.14 & -6.76 & -0.92 & -1.17 \\
\hline 3 & -36.20 & -35.92 & -36.89 & 5.37 & -1.89 & -4.22 \\
\hline Delta & 1.31 & 0.96 & 2.40 & 16.79 & 4.14 & 2.53 \\
\hline Rank & 2 & 3 & 1 & 1 & 2 & 3 \\
\hline
\end{tabular}

Smaller is better
Moreover, it should be mentioned that thermal properties and the thickness of the work material plays important role in laser drilling process [4]. For example, thermal diffusivity of nickel-based alloys is low; thus, at high peak power, less heat is absorbed and diffused throughout the workpiece surroundings. This result in more localised molten at the cut front and the drag force exerted by the assist process gas is not capable of expelling out significant portion of the molten material at each end of the pulse, thus increase in the RLT. This explains the responses obtained in this study when laser drilling at high peak power level.

The effect of pulse frequency on the average RLT $_{\text {max }}$ of the laser trepanned drill surface is shown in Fig. 7, plot (B). The pulse frequency is a less significant factor affecting average $\mathrm{RLT}_{\text {max }}$ under the range of values tested. However, a substantial increase in the pulse frequency can increase the substrate temperature and melt formation [9]. This is due to the increase in laser average power being transferred to the substrate material and also the time between successive pulses becoming too short to allow the molten material to be completely removed before the start of the subsequent pulse [7, 22]. Therefore, this could result in a poor vaporisation rate and consequently causing a thicker recast layer. A study elsewhere [9, 29] have demonstrated that a higher pulse frequency greater than $30 \mathrm{~Hz}$ produces a thicker recast layer. In this study, the higher level of pulse frequency of $25 \mathrm{~Hz}$ provided in overall a thin recast layer thickness.

The recast layer thickness can be minimised by using a low level of trepanning speed; see Fig. 9, plot (C). In this plot, the relationship between the trepanning speed and $\mathrm{RLT}_{\max }$ is shown. The response graph indicates that a higher trepanning speed leaves more recast layers around the sidewalls of the laser-drilled surface compared to a lower trepanning speed. This is because the increase in trepanning speed reduces the interaction time between the laser beam and surface, resulting in decrease of laser intensity delivered during the drilling 
Fig. 9 Main effect plots for $\mathrm{S} / \mathrm{N}$ ratios for maximum recast layer thickness

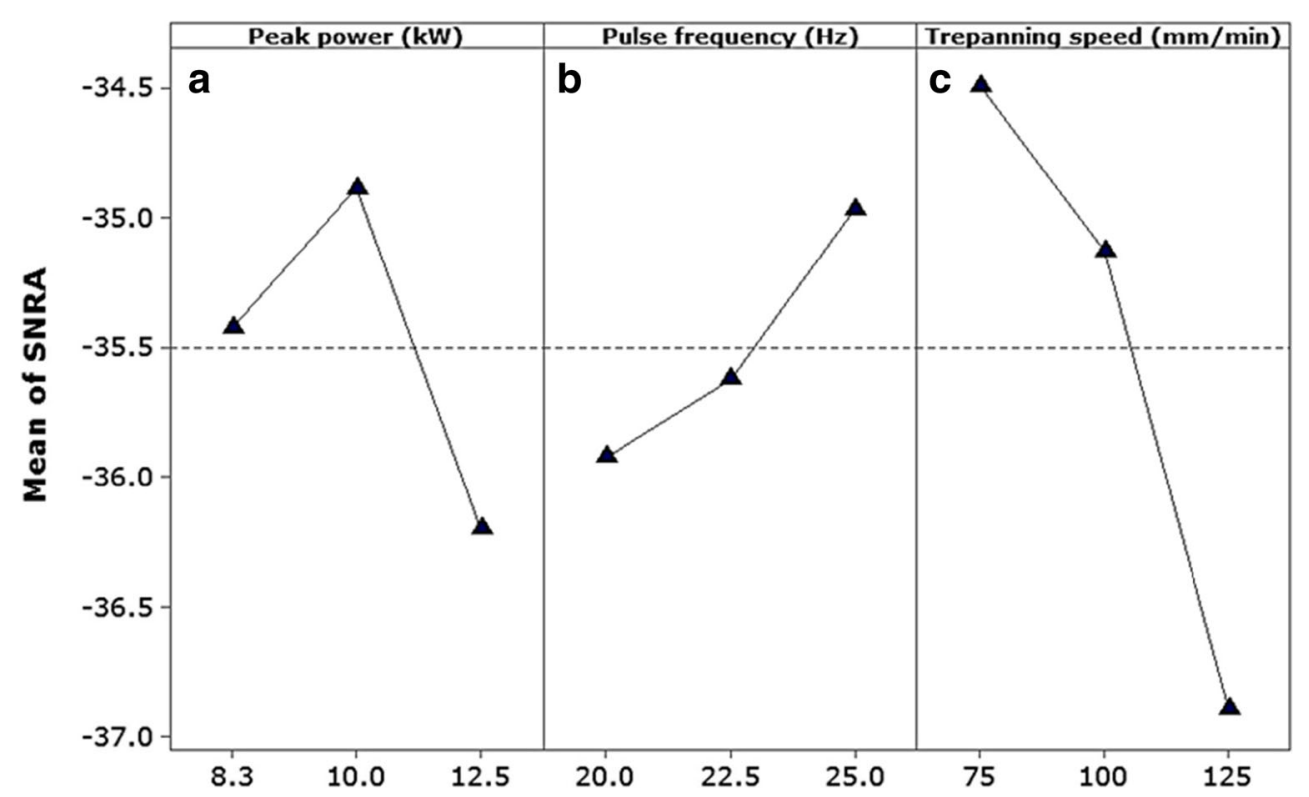

process. Also, increase in the speed results in a reduction of laser beam overlap, which eventually reduces the performance of material removal.

The preferable combination of control parameter levels for minimum average $\mathrm{RLT}_{\max }$ based on the $\mathrm{S} / \mathrm{N}$ ratio response (see Fig. 9) are $\mathrm{A} 2, \mathrm{~B} 3$ and $\mathrm{C} 1$, under the range of values tested. This means by setting the peak power to a moderate level will provide enough laser power for effective processing rate to achieve $\mathrm{RLT}_{\max }$ less than $50 \mu \mathrm{m}$. The pulse frequency at a high level will provide enough pulse time for effective material melting, vaporisation and ejection. Lastly, a trepanning speed at low levels can deliver a more robust process at cut front. However, demands of manufacturing demand the highest trepanning speed which can be achieved at an acceptable RLT.

\subsubsection{Crack number density}

The presence of microcracks within the recast layers is mainly associated with two main physical phenomena related to laser processing: rapid heating and rapid cooling rate (due to assist gas pressure). The rapid heating and rapid cooling effect causes large temperature gradients near the hole surface. This usually occurs at the hole entrance of the workpiece where the laser beam has usually higher heat effect for the ablation and the workpiece is cold (typically at a room temperature). On the other hand, the rapid cooling effect gets
Fig. 10 Main effects of mean $\mathrm{S} / \mathrm{N}$ ratio response plot for transverse crack number density $\left(\mathrm{TCND}_{\max }\right)$

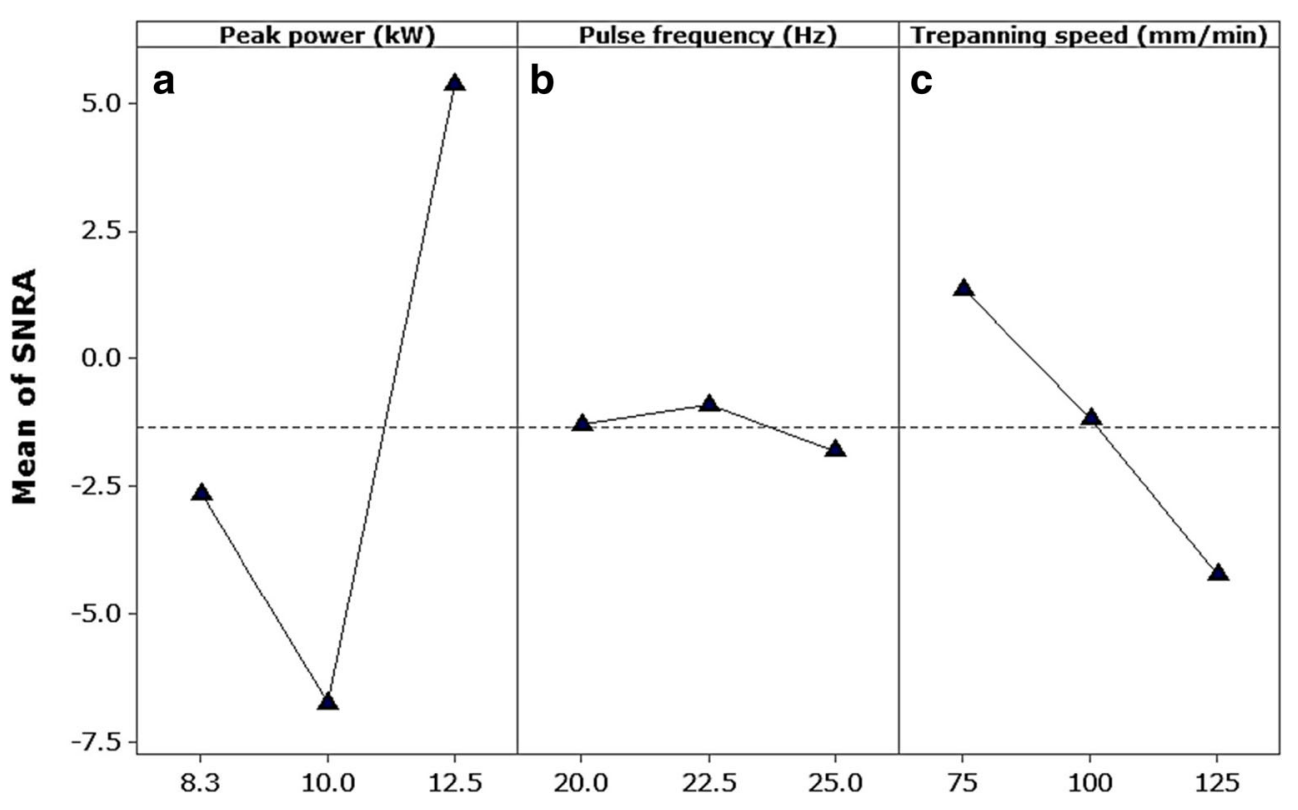


Table 4 Analysis of variance for the average RLT $_{\max }$

\begin{tabular}{llllll}
\hline Sources & Degree of freedom & $\begin{array}{l}\text { Adjusted sum } \\
\text { of squares }\end{array}$ & $\begin{array}{l}\text { Adjusted mean } \\
\text { of squares }\end{array}$ & $F$ value & \% Contribution \\
\hline$[\mathrm{A}]$ & 2 & 116.16 & 58.08 & 1.83 & 16.34 \\
{$[\mathrm{~B}]$} & 2 & 70.45 & 35.22 & 1.11 & 9.81 \\
{$[\mathrm{C}]$} & 2 & 460.51 & 230.25 & 7.25 & 64.80 \\
Error & 2 & 63.53 & 31.76 & - & 8.93 \\
Total & 8 & 710.64 & - & - & 100 \\
\hline
\end{tabular}

predominant in the middle and lower region of the drilled hole. This is because the laser beam energy is reduced as it goes down the hole due to absorption. The presence of microcracks was confirmed in every sample examined, but crack number density was different. This observation indicates that the different laser drilling parameters yield different crack densities. In this study, transverse crack number density was evaluated due to the detrimental influence of such cracks could potentially have on the fatigue life of laser-drilled component. The highest $\mathrm{TCND}_{\max }\left(2.75 \mathrm{no} . / \mathrm{mm}^{2}\right)$ and lowest $\left(0.25 \mathrm{no} . / \mathrm{mm}^{2}\right)$ occurs in trials 5 and 8 respectively. Figure 10 shows the effect of input control parameters on the $\mathrm{TCND}_{\max }$.

It can be seen from the Fig. 10, plot (A) that the degree $\mathrm{TCND}_{\text {max }}$ decreases as the peak power increases. The higher value of $\mathrm{TCND}_{\max }$ occurs at a moderate peak power because the internal thermal stresses inflicted on the workpiece are higher due to the pulse duration value set. This observation confirms that different combination of pulse duration and pulse energy values that configure the peak power could influence the cracking in the laser trepanning drilling. This trend has also been observed in previous studies on the $\mathrm{Nd}$ :YAG laser percussion drilling of vertical holes [23, 36] when laser processing is performed with longer pulse duration. The experimental results indicate that the peak power is a significant factor affecting the $\mathrm{TCND}_{\max }$ independent of whether trepanning or percussion is adopted. Further, the SEM measurement and observation indicates that the transverse microcracks were prominent when the RLT was greater than $20 \mu \mathrm{m}$ and located in the middle and the exit sections of the laser-drilled hole.
Figure 10, plot (B) shows the effects of the pulse frequency

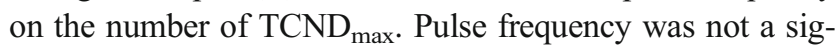
nificant control factor to affect the $\mathrm{TCND}_{\max }$ in the recast layers. However, increase in trepanning speed had relatively influenced the TCND $_{\max }$ (see Fig. 10, plot (C)). This is because the increase in trepanning speed also causes rapid heating and faster cooling effect in the laser-drilled area. This result in a sudden thermal mismatch and leads to the formation of cracks, thus increase in the crack number density.

To minimise the $\mathrm{TCND}_{\max }$ in the recast layers, the preferable combination of the levels is A3B2C1 under the $\mathrm{S} / \mathrm{N}$ ratio response, as depicted in Fig. 10. This means that for acute angled laser, drilled holes with negligible crack density can be achieved by setting high peak power, moderate pulse frequency and trepanning speed at the lowest level under the range of values tested. However, the choice of high peak power value should not be at the expense of thick recast layer.

\subsection{Analysis of variance}

Analysis of variance was conducted to determine the influence of the peak power, pulse frequency and trepanning speed on the $\mathrm{RLT}_{\max }$ and $\mathrm{TCND}_{\max }$. The analysis was conducted at 95\% confidence level. The significance of input control factors is determined by comparing the $F$ values of each input control factor. The last column of the table shows the percentage (\%) contribution value of each control factor, which directs the degree of influence on the laser drilling performance. Table 4 shows the results of the ANOVA associated with average $\mathrm{RLT}_{\text {max }}$ around the cross-sectioned laser-drilled samples. As shown in Table 4, it confirms that the trepanning speed
Table 5 Analysis of variance for $\mathrm{TCND}_{\max }$

\begin{tabular}{llllll}
\hline Source & Degree of freedom & $\begin{array}{l}\text { Adjusted sum } \\
\text { of squares }\end{array}$ & $\begin{array}{l}\text { Adjusted mean } \\
\text { of squares }\end{array}$ & $F$ value & \% Contribution \\
\hline$[\mathrm{A}]$ & 2 & 5.54 & 2.77 & 10.23 & 79.1 \\
{$[\mathrm{~B}]$} & 2 & 0.87 & 0.43 & 1.62 & 12.4 \\
{$[\mathrm{C}]$} & 2 & 0.041 & 0.020 & 0.08 & 0.58 \\
Error & 2 & 0.541 & 0.270 & - & 7.72 \\
Total & 8 & 7.0 & - & - & 100 \\
\hline
\end{tabular}


$(64.80 \%)$ was shown to be the most significant factor affecting the average $\mathrm{RLT}_{\max }$ followed by the peak power $(16.34 \%)$ and pulse frequency $(9.81 \%)$ under the range of values tested.

Table 5 shows the results of the ANOVA associated with transverse crack number density $\left(\mathrm{TCND}_{\max }\right)$ observed around the cross-sectioned laser-drilled samples, particularly in the recast layers. As shown in Table 5, the peak power is a significant parameter affecting the transverse crack number density and having its contribution more than $79.1 \%$. The pulse frequency $(0.58 \%)$ and trepanning speed $(12.4 \%)$ had a negligible impact on the transverse crack density.

\section{Conclusions}

Pulsed Nd:YAG laser trepan drilling of a CMSX-4 nickelbased acute angled holes were investigated by considering key process parameter effect on the recast layer thickness and transverse crack number density. The following observations were made under the range of investigating values:

- The preferable conditions for the average $\mathrm{RLT}_{\max }$ less than or equal to $50 \mu \mathrm{m}$ was observed at $\mathrm{A} 2 \mathrm{~B} 3 \mathrm{C} 1$. Also, it is noted that the average $\mathrm{RLT}_{\max }$ is directly proportional to the trepanning speed. The highest average $\mathrm{RLT}_{\max }$ $(77.1 \mu \mathrm{m})$ and lowest average $\mathrm{RLT}_{\max }(50$ and $48 \mu \mathrm{m})$ are observed in trials 3,6 and 1 respectively.

- The preferable conditions for a negligible $\mathrm{TCND}_{\max }$ on the recast layers were observed at $\mathrm{A} 1 \mathrm{~B} 2 \mathrm{C} 1$ setting. $\mathrm{TCND}_{\max }$ decreased with increase in the peak power and at a lower trepanning speed. The highest TCND ${ }_{\max }(2.75$ no. $\left./ \mathrm{mm}^{2}\right)$ and lowest $\mathrm{TCND}_{\max }\left(0.25 \mathrm{no} . / \mathrm{mm}^{2}\right)$ occur in trials 5 and 8 respectively.

- According to the analysis of variance results, it was found that the trepanning speed was the most significant control factor for average $\mathrm{RLT}_{\max }$ with the contribution of $64.80 \%$ and that the peak power was the most significant parameter among all contributing $79.10 \%$ for $\mathrm{TCND}_{\max }$. Pulse frequency had a small effect on the average RLT $_{\max }$ and $\mathrm{TCND}_{\max }$ within the range of values tested.

- Furthermore, the laser peak power which is a combination of pulse duration and the pulse energy is the main driver for the recast layer and microcrack formation; adjusting these two parameters and taking to account the trepanning speed interaction may improve the overall surface quality of the laser-drilled surface and provide a minimum amount of metallurgical defects.

- The work developed in this paper contributes to understanding of the recast and crack formation during the laser trepanning drilling process and how this knowledge can be used to enhance the current capabilities of this manufacturing technology for drilling high-quality angled cooling holes and hence improve the fatigue life.
Acknowledgements The authors are thankful to the Engineering and Physical Science Research Council for financial support of the research work (grant number EP/I033246/1) and Rolls-Royce Plc for the technical support and useful discussions. The laser drilling facilities provided by Manufacturing Technology Centre (MTC), Ansty, are gratefully acknowledged.

Open Access This article is distributed under the terms of the Creative Commons Attribution 4.0 International License (http:// creativecommons.org/licenses/by/4.0/), which permits unrestricted use, distribution, and reproduction in any medium, provided you give appropriate credit to the original author(s) and the source, provide a link to the Creative Commons license, and indicate if changes were made.

\section{References}

1. Tam S, Williams R, Yang L, Jana S, Lim L, Lau M (1990) A review of the laser processing of aircraft components. J Mater Process Technol 23(2):177-194. https://doi.org/10.1016/0924-0136(90) 90156-O

2. Yeo C, Tam S, Jana SLM (1994) A technical review of the laser drilling of aerospace materials. J Mater Process Technol 42(1):1549. https://doi.org/10.1016/0924-0136(94)90073-6

3. Voisey K, Clyne T (2004) Laser drilling of cooling holes through plasma sprayed thermal barrier coatings. Surf Coatings Technol 176(3):296-306. https://doi.org/10.1016/S0257-8972(03)00748-5

4. McNally CA, Folkes J, Pashby IR (2004) Laser drilling of cooling holes in aeroengines: state of the art and future challenges. Mater Sci Technol 20(7):805-813. https://doi.org/10.1179/ 026708304225017391

5. Dimov S, Petkov P, Minev R, Pham D (2008) Laser milling: pulse duration effects on surface integrity. Proc Inst Mech Eng Part B J Eng Manuf 222:35-45

6. Low DKY, Li L, Byrd PJ (2000) The effects of process parameters on spatter deposition in laser percussion drilling. Opt Laser Technol 32(5):347-354. https://doi.org/10.1016/S0030-3992(00)00079-7

7. Leigh S, Sezer K, Li L, Grafton-Reed C, Cuttell M (2010) Recast and oxide formation in laser-drilled acute holes in CMSX-4 nickel single-crystal superalloy. Proc Inst Mech Eng Part B J Eng Manuf 224(7):1005-1016. https://doi.org/10.1243/09544054JEM1541

8. Sezer H, Li L, Schmidt M, Pinkerton A, Anderson B, Williams P (2006) Effect of beam angle on HAZ, recast and oxide layer characteristics in laser drilling of TBC nickel superalloys. Int J Mach Tools Manuf 46(15):1972-1982. https://doi.org/10.1016/j. ijmachtools.2006.01.010

9. Duan W, Wang K, Dong X, Mei X, Wang W, Fan Z (2014) Experimental characterizations of burr deposition in Nd:YAG laser drilling: a parametric study. Int J Adv Manuf Technol 76:15291542

10. Schneider M, Berthe L, Muller M, Fabbro R (2010) A fast method for morphological analysis of laser drilling holes. J Laser Appl 22(4):127-131. https://doi.org/10.2351/1.3508232

11. Yilbas BS (1985) The study of laser produced plasma behaviour using streak photography. Jpn J Appl Phys 24:1417-1420. https:// doi.org/10.1143/JJAP.24.1417

12. Garofano J, Marcus H, Aindow M (2009) Characterization of microstructural effects in a percussion laser-drilled powder metallurgy Ni-based superalloy. J Mater Sci 44(2):680-684. https://doi.org/10. 1007/s10853-008-3177-x

13. Garofano J, Marcus H, Aindow M (2010) Extraction replication studies of near-surface microstructures in laser-drilled samples of 
the powder metallurgy Ni-based superalloy IN100. Mater Charact 61(10):929-936. https://doi.org/10.1016/j.matchar.2010.06.003

14. Schneider M (2007) New experimental approach to study laser matter interaction during drilling in percussion regime. J Laser Micro/Nanoengineering 2(2):117-122. https://doi.org/10.2961/ jlmn.2007.02.0002

15. Beck T (2011) Laser drilling in gas turbine blades shaping of holes in ceramic and metallic coatings. Laser Tech J 8(3):40-43. https:// doi.org/10.1002/latj.201190024

16. van Dijk MH (1992) Drilling of aero-engine components: experiences from the shop floor. In: Belforte D, Leviit M (eds) The Industrial Laser Handbook. Springer, pp 113-118. https://doi.org/ 10.1007/978-1-4612-2882-0 12

17. Goyal R, Dubey AK (2014) Quality improvement by parameter optimization in laser trepan drilling of superalloy sheet. Mater Manuf Process 29(11-12):1410-1416. https://doi.org/10.1080/ 10426914.2014.912313

18. Bandyopadhyay S, Sarin SJ, Sundararajan G, Joshi S (2002) Geometrical features and metallurgical characteristics of Nd:YAG laser drilled holes in thick IN718 and Ti-6Al-4V sheets. J Mater Process Technol 127(1):83-95. https://doi.org/10.1016/S09240136(02)00270-4

19. Pandey ND, Shan HS, Mohandas T (2006) Percussion laser-drilled holes: characteristics and characterization procedure. Mater Manuf Process 21(4):383-391. https://doi.org/10.1080/ 10426910500411652

20. Mishra S, Yadava V (2013) Modeling and optimization of laser beam percussion drilling of nickel-based superalloy sheet using Nd: YAG laser. Opt Lasers Eng 51(6):681-695. https://doi.org/10. 1016/j.optlaseng.2013.01.006

21. Corcoran A, Sexton L, Seaman B, Ryan P, Bryne G (2002) The laser drilling of multi-layer aerospace material systems. J Mater Process Technol 123(1):100-106. https://doi.org/10.1016/S09240136(01)01123-2

22. Leigh S, Sezer K, Li L, Grafton-Reed C, Cuttell M (2009) Statistical analysis of recast formation in laser drilled acute blind holes in CMSX-4 nickel superalloy. Int J Adv Manuf Technol 43(11-12):1094-1105. https://doi.org/10.1007/s00170-008-1789-6

23. Bathe R, Padmanabham G (2014) Evaluation of laser drilling of holes in thermal barrier coated superalloys. Mater Sci Technol 30(14):1778-1782. https://doi.org/10.1179/1743284713Y. 0000000477

24. Horn A, Weichenhain R, Albrecht S, Kreutz EW, Michel J, Niessen M, Kostrykin V, Schulz W, Etzkorn A, Bobzin K, Lugscheider E (2000) Microholes in zirconia coated Ni-superalloys for transpiration cooling of turbine blades. Proc SPIE Int Soc Opt Eng 4065:218-226

25. Grafton-Reed C (2008) Brief insight into Rolls-Royce laser manufacturing technologies. Ind Oppor laser micro nano Process - AILU Technol Work:1-9

26. Willach J, Kreutz E, Michel J, Niessen M, Schulz W, Poprawe R (2003) Melt expulsion by a coaxial gas jet in trepanning of CMSX4 with microsecond Nd:YAG laser radiation. Fourth Int Symp laser Precis Microfabr 5063:435-440

27. Lugscheider E, Bobzin K, Maes M, Lackner K, Poprawe R, Kreutz E, Willach J (2005) Laser drilled microholes in zirconia coated surfaces using two variants to implement the effusion cooling of first stage turbine blades. Adv Eng Mater 7(3):145-152. https://doi. org/10.1002/adem.200400148

28. Kreutz EW, Trippe L, Walther K, Poprawe R (2007) Process development and control of laser drilled and shaped holes in turbine components. J Laser Micro/Nanoengineering 2(2):123-127. https://doi.org/10.2961/jlmn.2007.02.0003

29. Chien WT, Hou SC (2007) Investigating the recast layer formed during the laser trepan drilling of Inconel 718 using the Taguchi method. Int J Adv Manuf Technol 33(3-4):308-316. https://doi.org/ 10.1007/s00170-006-0454-1

30. Wang K, Duan W, Mei X, Wang W (2012) Technology to drill micro-holes without recast layer by laser on nickel-based alloy. In: Advanced Materials Research. pp 303-307

31. Kumar S, Dubey AK, Pandey AK (2013) Computer-aided genetic algorithm based multi-objective optimization of laser trepan drilling. Int J Precis Eng Manuf 14(7):1119-1125. https://doi.org/10. 1007/s12541-013-0152-5

32. French PW, Naeem M, Sharp M, Watkins KG, (2006) Investigation into the influence of pulse shaping on drilling efficiency. In ICALEO 2006 Proceedings. Laser Institute of America, Orlando, FL (United States), Paper 310

33. French PW, Hand DP, Peters C, Shannon GJ, Byrd P, Steen WM (1998) Investigation of the Nd: YAG laser percussion drilling process using high speed filming. ICALEO 98 Proc 85:1-10

34. Fullagar KPL, Broomfield RW, Hulands M, Harris K, Erickson GL, Sikkenga SL (1996) Aero engine test experience with CMSX-4® alloy single-crystal turbine blades. J Eng Gas Turbines Power 118(2):380-388. https://doi.org/10.1115/1.2816600

35. Roy RK (2010) A primer on the Taguchi method, 2nd ed. Society of Manufacturing Engineers

36. Corcoran A, Sexton L (2000) The laser drilling of multi-layer Rene 80 and X40 material systems. Laser Mater Process 89:163172 